\title{
An Early Look at Rates of Uninsured Safety Net Clinic Visits After the Affordable Care Act
}

\author{
Heather Angier, MPH \\ Megan Hoopes, $\mathrm{MPH}^{2}$ \\ Racbel Gold, $\mathrm{PbD}, \mathrm{MPH}^{2,3}$ \\ Steffani R. Bailey, $P b D^{1}$ \\ Erika K. Cottrell, $P b D, M P P^{1,2}$ \\ Jobn Heintzman, $M D^{1}$ \\ Miguel Marino, $\mathrm{PbD}^{1}$ \\ Jennifer E. DeVoe, MD, DPbil ${ }^{1,2}$ \\ ${ }^{1}$ Oregon Health \& Science University, \\ Portland, Oregon \\ ${ }^{2} \mathrm{OCHIN}$, Inc, Portland, Oregon
}

${ }^{3}$ Kaiser Permanente Northwest Center for Health Research, Portland, Oregon
Conflicts of interest: authors report none.

\section{CORRESPONDING AUTHOR}

Heather Angier, MPH Oregon Health \& Science University 3181 SW Sam Jackson Park Rd Mailcode: FM

Portland, OR 97239

angierh@ohsu.edu

\begin{abstract}
PURPOSE The Affordable Care Act of 2010 supports marked expansions in Medicaid coverage in the United States. As of January 1, 2014, a total of 25 states and the District of Columbia expanded their Medicaid programs. We tested the hypothesis that rates of uninsured safety net clinic visits would significantly decrease in states that implemented Medicaid expansion, compared with states that did not.
\end{abstract}

METHODS We undertook a longitudinal observational study of coverage status for adult visits in community health centers, from 12 months before Medicaid expansion (January 1, 2013 to December 31, 2013) through 6 months after expansion (January 1, 2014 to June 30, 2014). We analyzed data from 156 clinics in the OCHIN practice-based research network, with a shared electronic health record, located in 9 states ( 5 expanded Medicaid coverage and 4 did not).

RESULTS Analyses were based on 333,655 nonpregnant adult patients and their $1,276,298$ in-person billed encounters. Overall, clinics in the expansion states had a $40 \%$ decrease in the rate of uninsured visits in the postexpansion period and a $36 \%$ increase in the rate of Medicaid-covered visits. In contrast, clinics in the nonexpansion states had a significant $16 \%$ decline in the rate of uninsured visits but no change in the rate of Medicaid-covered visits.

CONCLUSIONS There was a substantial decrease in uninsured community health center visits and a significant increase in Medicaid-covered visits in study clinics in states that expanded Medicaid in 2014, whereas study clinics in states opting out of the expansion continued to have a high rate of uninsured visits. These findings suggest that Affordable Care Act-related Medicaid expansions have successfully decreased the number of uninsured safety net patients in the United States.

Ann Fam Med 2015;13:10-16. doi: 10.1370/afm.1741.

\section{INTRODUCTION}

H ealth insurance facilitates access to care and reduces unmet health care needs ${ }_{1}^{1-4}$ yet 47 million Americans did not have coverage in 2012. ${ }^{5}$ The Patient Protection and Affordable Care Act of 2010 (ACA), the largest health care-related legislation in the United States since Medicare's establishment in 1966, was enacted with the goal of expanding coverage to all citizens and legal residents. ${ }^{6}$ The ACA calls for expansions in Medicaid coverage to individuals making up to $138 \%$ of the federal poverty level (FPL). In 2012, the Supreme Court ruled that states were not legally required to implement the ACA-sponsored Medicaid expansions, and those opting out could not be penalized. ${ }^{7}$ As of January 1 , 2014, a total of 25 states and the District of Columbia had expanded their Medicaid programs. ${ }^{8}$

Estimates from previous studies suggested that 13 to 22 million individuals would gain Medicaid coverage after ACA implementation, ${ }^{9-11}$ and some actual results are now known. ${ }^{12,13}$ By June 2014, 7.2 million people were newly enrolled in Medicaid programs through the $\mathrm{ACA}_{1}{ }^{13}$ and since late 2013, the number of Americans without health insurance dropped by approximately 8.0 million. ${ }^{12}$ Many persons directly affected by these 
expansions are seen at community health centers (CHCs), which comprise much of our nation's health care safety net, and serve a rapidly increasing number of patients regardless of their ability to pay ${ }^{14}$; in 2012, 36\% of CHC patients were uninsured.$^{15}$ Little is known, however, about the effects of the ACA expansions on the rate of uninsured safety net visits in states that did vs did not implement the Medicaid expansion.

This study compared rates of $\mathrm{CHC}$ visits by coverage status in the first 6 months after the ACA's Medicaid expansions began, with those in the year before expansion. We tested the hypothesis that expansion will significantly decrease rates of uninsured $\mathrm{CHC}$ visits, and that rates of visits covered by insurance, particularly Medicaid, will increase significantly in CHCs in states that implemented Medicaid expansion, compared with states that did not.

\section{METHODS}

\section{Data Source and Study Population}

We used electronic health record data from the Oregon Community Health Information Network, renamed OCHIN as other states joined, a multistate collaboration of health systems. ${ }^{16,17}$ This unique national organization facilitates implementation of electronic health records in CHCs and supports a practice-based research network. All OCHIN member clinics share a centrally hosted, linked instance of the EpicCare electronic health record (EPIC Systems). Almost all OCHIN clinic patients are from households below $200 \%$ of the FPL. ${ }^{16-18}$ We included a convenience sample of any $\mathrm{CHCs}$ having active status on OCHIN's electronic health record as of January 1,2013 , totaling $167 \mathrm{CHCs}$ in 11 states. We excluded CHCs from Texas because the majority of our eligible patient population was covered by a state-funded program similar to Medicaid in the preexpansion and postexpansion periods. We also excluded clinics in Wisconsin because their previously closed Medicaid program was opened to new applicants in 2014, so that state resembled an expansion state despite its nonexpansion status. After these exclusions, we had $156 \mathrm{CHCs}$ located in 5 Medicaid expansion states (California, Minnesota, Ohio, Oregon, and Washington) and 4 nonexpansion states (Alaska, Indiana, Montana, and North Carolina). We included all faceto-face primary care visits by nonpregnant adults aged 19 to 64 years in the study period. Encounters were collected from 12 months before expansion (January 1, 2013 to December 31, 2013) through 6 months after expansion (January 1, 2014 to June 30, 2014) resulting in a total sample size of 333,655 patients with $1,276,298$ encounters.

\section{Variables}

Our outcomes were rates of uninsured, Medicaidinsured, and commercially insured CHC visits in the preexpansion vs postexpansion periods overall, and by month across the 18 -month study period. The primary independent variable was expansion status: whether or not a state expanded Medicaid eligibility to at least $138 \%$ of the FPL as of January 1, 2014.

\section{Data Analysis}

We computed $\chi^{2}$ statistics to compare patient panel characteristics between the study CHCs in expansion vs nonexpansion states. We conducted a 2 -group longitudinal preexpansion vs postexpansion analysis where we compared visit rates in each period by expansion status. For greater detail about changes in visit rates, we did a preexpansion vs postexpansion analysis for each state. Generalized estimating equation Poisson models with compound symmetry correlation structure and empirical sandwich variance estimator were fitted to obtain rates and rate ratios (RRs) for the preexpansion and postexpansion periods with $95 \% \mathrm{CIs}$, accounting for temporal correlation within $\mathrm{CHCs}$, and adjusting for significant $\mathrm{CHC}$ and state-level covariates. We fitted similar regression models to obtain visit rates by month across the study period.

To account for differences in the composition of the $\mathrm{CHCs}^{\prime}$ patient panels, we adjusted for clinic-level frequencies of sex, age, race, ethnicity, urban vs rural residence, and household income. When comparing expansion vs nonexpansion status, we also assessed potential state-level economic covariates: 2014 minimum wage ${ }^{19}$ and unemployment rates, ${ }^{20}$ and the 2013 rate of uninsured adults. ${ }^{21}$ Significant covariates $(P<.05)$ from an initial multivariable model were retained in final models. All statistical analyses were done using SAS version 9.3 (SAS Institute, Inc). This study was reviewed and approved by the Oregon Health \& Science University Institutional Review Board.

\section{RESULTS}

At the start of the study period, CHCs in states that expanded Medicaid eligibility had younger patients, more patients under $138 \%$ of the FPL, fewer nonwhite patients, more Hispanic patients, and more patients in urban areas $(P<.001$ for all, Table 1$)$. The overall encounter rate in the postexpansion period increased by $5 \%$ compared with the rate in the prior year in expansion state $\mathrm{CHCs}(\mathrm{RR}=1.05 ; 95 \% \mathrm{CI}, 1.01-1.08$; $P=.01)$; the encounter rate remained unchanged across $\mathrm{CHCs}$ in nonexpansion states $(\mathrm{RR}=0.95 ; 95 \% \mathrm{CI}$, $0.87-1.04 ; P=.25$ ).

The rate of Medicaid-covered visits increased sig- 
Nonexpansion States ${ }^{8}$

\section{AK}

IN

MT

NC

Total

$78 / 128$

$$
7.50
$$

6.4

18.9

Federal

$$
\begin{gathered}
24 / 24 \\
7.25 \\
5.7 \\
15.3 \\
\text { Federal }
\end{gathered}
$$

$$
\begin{gathered}
54 / 54 \\
7.90 \\
4.6 \\
20.7 \\
\text { Federal }
\end{gathered}
$$

\author{
5
}

9,014

$5,265(58.4)$

$1,221(55.6)$

347 (15.8)

$760(34.6)$

$1,091(49.6)$

$718(32.7)$

$1,016(46.2)$

464 (21.1)

$647(29.4)$

$227(10.3)$

$2,172(98.8)$

$0.94^{h}$
$0.84^{h}$
$1.07^{h}$
$0.96^{h}$

9
244

$6,700(65.4)$

$1,469(14.3)$

$3,091(30.2)$

$5,684(55.5)$

7,507 (73.3)

$1,038(10.1)$

$1,699(16.6)$

$5,704(55.7)$

$1,041(10.2)$

10,195 (99.5)
$1,876(20.8)$

$2,569(28.5)$

$4,569(50.7)$

$5,431(60.3)$

$2,181(24.2)$

$1,402(15.6)$

$332(3.7)$

$336(3.7)$

$8,083(89.7)$

\section{$47 / 45$}

7.25

6.4

20.4

Federal

$4 \quad 19$

11,861

7,004 (59.1)

$1,269(10.7)$

$2,683(22.6)$

$7,909(66.7)$

$5,410(45.6)$

$2,822(23.8)$

$3,629(30.6)$

$6,783(57.2)$

491 (4.1)

$8,886(74.9)$

0.93

(0.80-1.08)

0.78

(0.57-1.07)

0.96

(0.81-1.12)

1.03

(0.99-1.06)
33,315

$20,188(60.6)$

4,961 (14.9)

$9,102(27.3)$

$19,252(57.8)$

19,066 (57.2)

$7,055(21.2)$

$7,194(21.6)$

$13,466(40.4)$

$2,095(6.3)$

$29,335(88.1)$

0.95

(0.87-1.04)

0.84

$(0.74-0.95)^{9}$

1.05

(0.94-1.18)

1.03

(0.96-1.11)

the postexpansion period, but the difference between the preexpansion vs postexpansion periods was not statistically significant $(P=.44)$.

\section{DISCUSSION}

\section{Main Findings}

This study, the first to use electronic health record data to measure changes in $\mathrm{CHC}$ encounter coverage rates after ACA Medicaid expansions, found a $40 \%$ decrease in the rate of uninsured $\mathrm{CHC}$ visits in study Medicaid expansion states in 2014. Our findings confirm other reports showing increased health insurance coverage rates subsequent to state Medicaid expansion ${ }^{12,24,25}$ and add new information demonstrating a measurable effect on $\mathrm{CHC}$ visits in expansion states.

Although millions will gain Medicaid coverage after ACA implementation,, 910 it is also estimated that as many as $42 \%$ of adults who have not had insurance will continue to be without coverage options in states that have decided not to expand Medicaid, ${ }_{1}^{26,27}$ and that income-based inequalities will persist. ${ }^{28} \mathrm{CHCs}$ will therefore likely continue to play a vital role in providing health care to vulnerable populations after the ACA, especially for adults in nonexpansion states who earn too much to qualify for Medicaid, but too little to afford private coverage ${ }^{29}$ This population, estimated at nearly 5 million adults, has very limited coverage options and faces barriers to health care access. ${ }^{27}$ If every state participated in Medicaid expansions, such disparities in health care coverage and access could be mitigated. ${ }^{30}$ Additionally, the benefit of eliminating these disparities could reach beyond individual adult patients, affecting children and others in the household. ${ }^{29,31,32}$

Uninsured visits among study CHCs in California showed little change during the study period, which could be due to the

Figure 2 presents monthly visit coverage rates for $\mathrm{CHCs}$ by expansion status. In the first month postexpansion, the rate of Medicaid-covered visits increased $32 \%$ in expansion state CHCs, with an average increase of 71 encounters per $\mathrm{CHC}$ per month. In the same states, the rate of uninsured visits declined throughout the postexpansion period. Among $\mathrm{CHCs}$ in states that did not expand Medicaid, a modest increase in commercially insured visit rates was seen in backlog of Medicaid applications after expansion. ${ }^{33}$ The modest decline in uninsured visit rates in nonexpansion states could be attributable to increased coverage options available through the ACA's insurance marketplaces, although we did not see an increase in commercially insured patients in nonexpansion states. Another explanation is that the capacity for seeing uninsured patients decreased in these states; more research is needed to better understand these findings. 


\section{Limitations}

This study was based on a convenience sample of primary care $\mathrm{CHC}$ s with a linked electronic health record. These CHCs are located in 9 states, some of which are represented by only a few $\mathrm{CHCs}_{\text {; }}$ thus, our results are not necessarily representative of the postACA experiences of all states, all CHCs in the study states, or expansion status groups. Our visit-based

Figure 1. Adjusted rates of uninsured visits by month among CHCs in expansion and nonexpansion states.

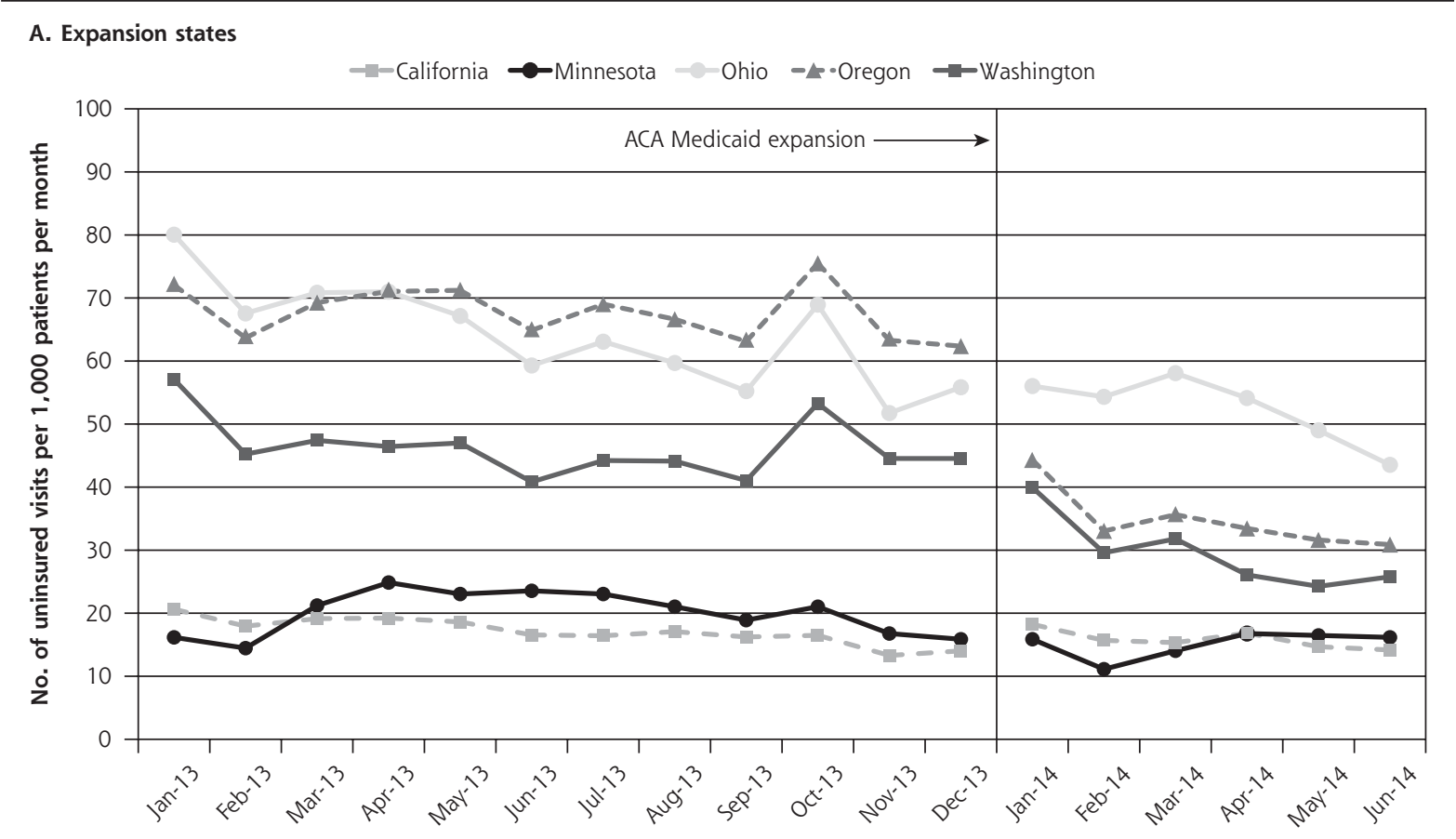

B. Nonexpansion states

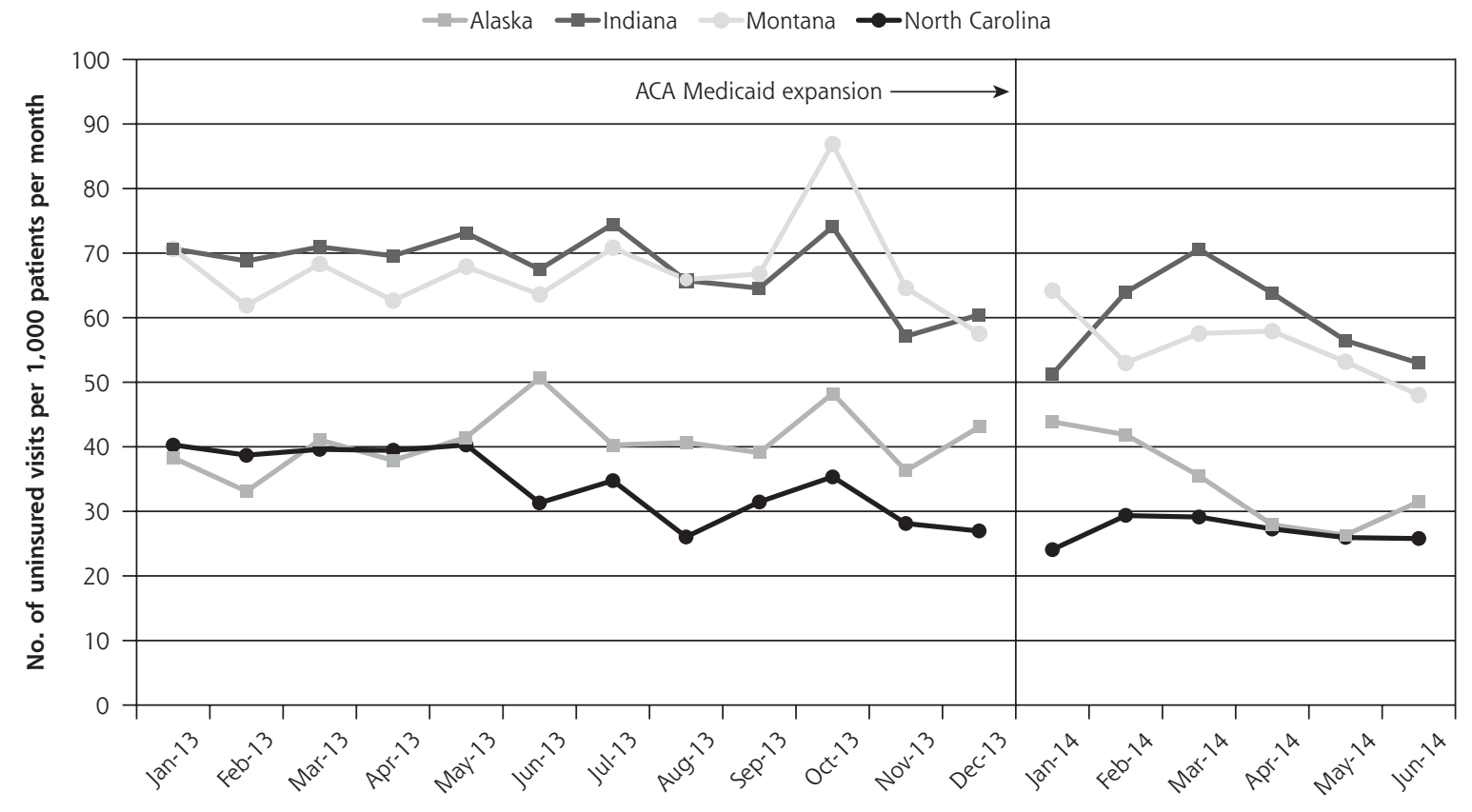

$\mathrm{ACA}=$ Affordable Care Act; $\mathrm{CHC}=$ community health center.

Notes: Rates calculated per 1,000 adult patients across entire study period. Poisson general estimating equation (GEE) model adjusted for percent of patients aged younger than 40 years and percent Hispanic, accounting for temporal correlation within CHCs over time. 
Figure 2. Adjusted visit rates by coverage status and month among CHCs in expansion and nonexpansion states.

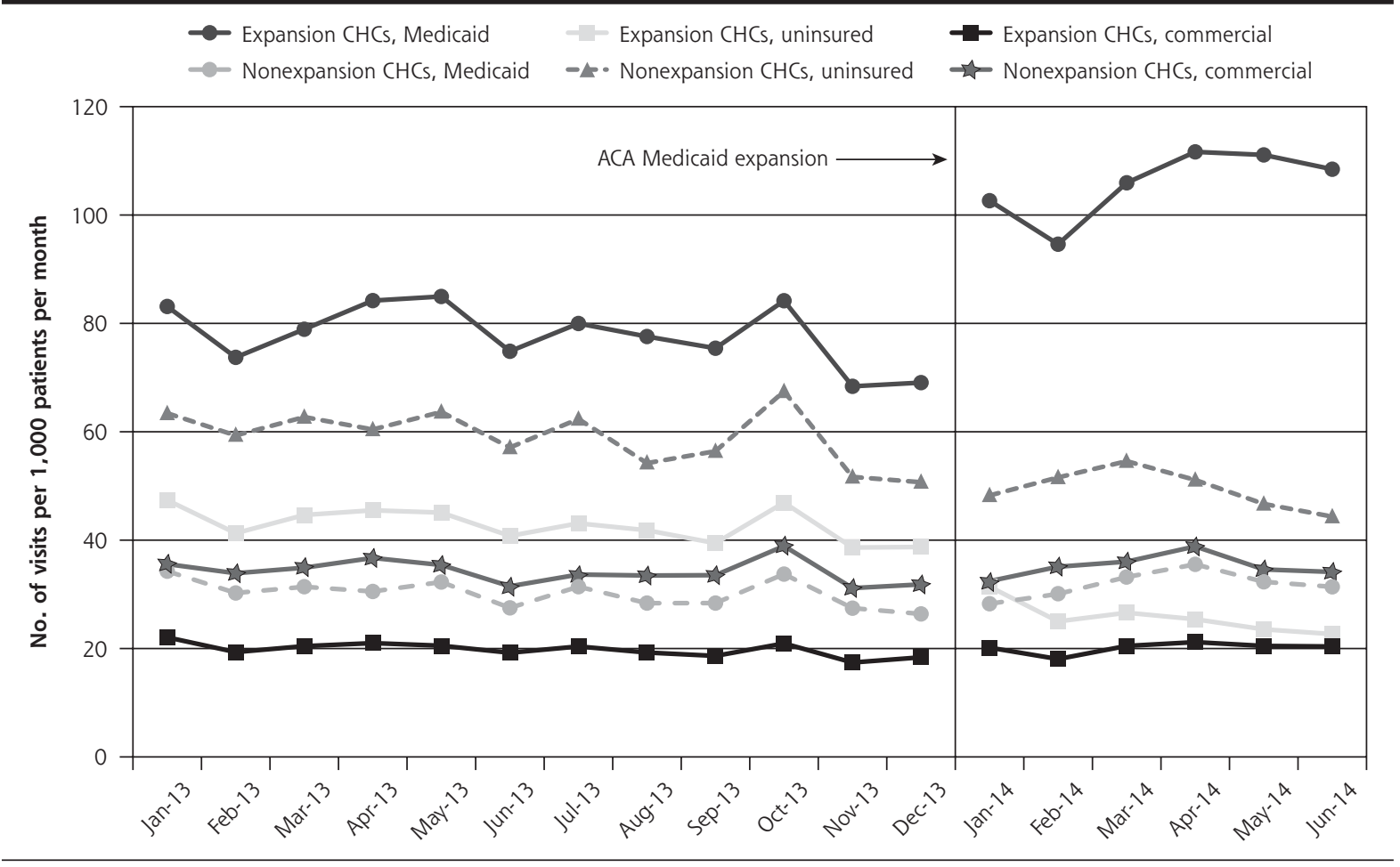

$\mathrm{ACA}=$ Affordable Care Act; $\mathrm{CHC}=$ community health center.

Notes: Rates calculated per 1,000 adult patients across entire study period. Poisson general estimating equation (GEE) model adjusted for percent nonwhite race, percent Hispanic, percent $\leq 138 \%$ federal poverty level (FPL), and percent with unknown FPL; models account for temporal correlation within CHCs over time.

analysis evaluates the impact of Medicaid expansion on safety net clinics, but does not capture changes in individuals' insurance status or patient panel characteristics. There were significant differences between expansion and nonexpansion states' $\mathrm{CHC}$ patients in our sample, which we attempted to account for through adjusted multivariate analysis and by using expansion states as their own control in preexpansion vs postexpansion period comparisons. We recognize, however, that unobserved confounders could potentially influence these results.

\section{Conclusion}

We found a significant decrease in uninsured $\mathrm{CHC}$ visits and a significant increase in Medicaid-covered visits in study clinics in states that expanded Medicaid in 2014, whereas study CHCs in states opting out of the expansion maintained a high rate of uninsured visits. These findings suggest that ACA-related Medicaid expansions have been successful in decreasing the number of uninsured safety net patients in the United States.

To read or post commentaries in response to this article, see it online at http://www.annfammed.org/content/13/1/10.
Key words: safety net clinics; uninsured; Affordable Care Act; practicebased research; primary care

Submitted September 26, 2014; submitted, revised, November 13, 2014; accepted November 19, 2014.

Funding support: This work was financially supported by the Patient-Centered Outcomes Research Institute (PCORI), the National Cancer Institute (NCl) of the National Institutes of Health, grant 1 R01 CA181452 01, and the Oregon Health \& Science University Department of Family Medicine.

Disclaimer: The funding agencies had no involvement in the design and conduct of the study; analysis and interpretation of the data; and preparation, review, or approval of the manuscript.

Acknowledgments: We thank the OCHIN practice-based research network and the clinics for assisting with this research.

\section{References}

1. Asplin BR, Rhodes KV, Levy H, et al. Insurance status and access to urgent ambulatory care follow-up appointments. JAMA. 2005;294(10):1248-1254.

2. Smolderen KG, Spertus JA, Nallamothu BK, et al. Health care insurance, financial concerns in accessing care, and delays to hospital presentation in acute myocardial infarction. JAMA. 2010;303(14): 1392-1400. 
3. Burstin HR, Lipsitz SR, Brennan TA. Socioeconomic status and risk for substandard medical care. JAMA. 1992;268(17):2383-2387.

4. Bindman AB, Grumbach K, Osmond D, et al. Preventable hospitalizations and access to health care. JAMA. 1995;274(4):305-311.

5. Kaiser Commission on Medicaid and the Uninsured. The uninsured: a primer - key facts about health insurance on the eve of health reform. http://kff.org/uninsured/report/the-uninsured-a-primer-keyfacts-about-health-insurance-on-the-eve-of-coverage-expansions/. Published Oct 23, 2013. Updated Dec 5, 2014. Accessed Aug 20, 2014.

6. Henry J. Kaiser Family Foundation. Summary of the Affordable Care Act. http://kff.org/health-reform/fact-sheet/summary-of-theaffordable-care-act/. Published Apr 25, 2013. Accessed Aug 12, 2014.

7. National Federation of Independent Business et al v Sebelius. 567 US 2012; http://www.supremecourt.gov/opinions/11pdf/11-393c3a2. pdf. Accessed Mar 4, 2014.

8. Kaiser Commission on Medicaid and the Uninsured. Medicaid eligibility for adults as of January 1, 2014. October 1, 2013. http:// $\mathrm{kff}$.org/medicaid/fact-sheet/medicaid-eligibility-for-adults-as-ofjanuary-1-2014/. Accessed Aug 20, 2014.

9. Sommers BD, Swartz K, Epstein A. Policy makers should prepare for major uncertainties in Medicaid enrollment, costs, and needs for physicians under health reform. Health Aff (Millwood). 2011;30(11):2186-2193.

10. Parente ST, Feldman R. Microsimulation of private health insurance and Medicaid take-up following the U.S. Supreme court decision upholding the Affordable Care Act. Health Serv Res. 2013;48(2 Pt 2): 826-849.

11. Blumenthal D, Collins SR. Health care coverage under the Affordable Care Act-a progress report. N Engl J Med. 2014;371(3):275-281.

12. Long SK, Kenney GM, Zuckerman S, et al. Taking stock at mid-year: health insurance coverage under the ACA as of June 2014. http:// hrms.urban.org/briefs/taking-stock-at-mid-year.html. Published Jul 29, 2014. Accessed Aug 12, 2014.

13. Department of Health and Human Services. Medicaid \& CHIP: June 2014 monthly applications, eligibility determinations, and enrollment report. http://medicaid.gov/AffordableCareAct/MedicaidMoving-Forward-2014/Downloads/June-2014-Enrollment-Report. pdf. Published Aug 8, 2014.

14. Morgan D. US health centers for poor, uninsured see ranks swell. May 1, 2012. http://www.reuters.com/article/2012/05/01/us-usahealthcare-centers-idUSBRE8401JL20120501. Accessed Feb 21, 2013.

15. National Association of Community Health Centers. A sketch of community health centers. Chart book 2014. 2014. http://www. nachc.com/client//Chartbook_2014.pdf.

16. Devoe JE, Sears A. The OCHIN community information network: bringing together community health centers, information technology, and data to support a patient-centered medical village. J Am Board Fam Med. 2013;26(3):271-278.

17. Devoe JE, Gold R, Spofford M, et al. Developing a network of community health centers with a common electronic health record: description of the Safety Net West Practice-based Research Network (SNW-PBRN). J Am Board Fam Med. 2011;24(5):597-604.

18. Hatch $B$, Angier $H$, Marino $M$, et al. Using electronic health records to conduct children's health insurance surveillance. Pediatrics. 2013; 132(6):e1584-e1591.
19. CNN. 2014 Minimum wage, state by state. National Employment Law Project. http://money.cnn.com/interactive/pf/state-minimumwage/. Accessed Aug 12, 2014.

20. Bureau of Labor Statistics. Current unemployment rates for states and historical highs/lows. http://www.bls.gov/web/laus/lauhsthl.htm. Accessed Aug 12, 2014.

21. Witters D. Highest uninsured states less likely to embrace health law. February 7, 2014. http://www.gallup.com/poll/167321/highestuninsured-states-less-likely-embrace-health-law.aspx. Accessed Aug 12, 2014.

22. Kaiser Commission on Medicaid and the Uninsured. Getting into gear for 2014: findings from a 50-state survey of eligibility, enrollment, renewal, and cost-sharing policies in Medicaid and CHIP, 2012-2013. http://kff.org/medicaid/report/getting-into-gear-for2014-findings-from-a-50-state-survey-of-eligibility-enrollmentrenewal-and-cost-sharing-policies-in-medicaid-and-chip-2012-2013/. Published Jan 23, 2013. Accessed Aug 20, 2014

23. Kaiser Commission on Medicaid and the Uninsured. State marketplace statistics. http://kff.org/health-reform/state-indicator/statemarketplace-statistics/\#note-7. Accessed Aug 20, 2014.

24. Clemans-Cope L, Long SK, Coughlin TA, Yemane A, Resnick D. The expansion of Medicaid coverage under the ACA: implications for health care access, use, and spending for vulnerable low-income adults. Inquiry. 2013;50(2):135-149.

25. Price CC, Eibner C. For states that opt out of Medicaid expansion: 3.6 million fewer insured and $\$ 8.4$ billion less in federal payments. Health Aff (Millwood). 2013;32(6):1030-1036.

26. Rasmussen PW, Collins SR, Doty MM, Garber T. In states' hands: how the decision to expand Medicaid will affect the most financially vulnerable Americans: findings from the Commonwealth Fund Health Insurance Tracking Surveys of U.S. Adults, 2011 and 2012. Issue Brief (Commonw Fund). 2013;23:1-8.

27. Kaiser Commission on Medicaid and the Uninsured. The coverage gap: uninsured poor adults in states that do not expand Medicaid. March 2014. http://kff.org/health-reform/issue-brief/the-coveragegap-uninsured-poor-adults-in-states-that-do-not-expand-medicaid/. Accessed Aug 4, 2014.

28. Collins SR, Robertson R, Garber T, Doty MM. The income divide in health care: how the Affordable Care Act will help restore fairness to the U.S. health system. Issue Brief (Commonw Fund). 2012;3:1-24.

29. Angier H, DeVoe JE, Tillotson CJ, Wallace LS. Changes in health insurance for US children and their parents: comparing 2003 to 2008. Fam Med. 2013:45(1):26-32.

30. Crowley RA, Golden W. Health policy basics: Medicaid expansion. Ann Intern Med. 2014;160(6):423-425.

31. Dubay L, Kenney G. The impact of CHIP on children's insurance coverage: an analysis using the National Survey of America's Families. Health Serv Res. 2009;44(6):2040-2059.

32. Angier H, DeVoe JE, Tillotson C, Wallace L, Gold R. Trends in health insurance status of US children and their parents, 1998-2008. Matern Child Health J. 2013;17(9):1550-1558.

33. Galewitz P. Kaiser Health News. More than 1.7 million consumers still wait for Medicaid decisions. http://kaiserhealth news.org/news/more-than-17-million-consumers-still-wait-formedicaid-decisions. Published Jun 9, 2014. Accessed Sep 26, 2014 